\title{
Diode Laser-Driven Microthrusters: A New Departure for Micropropulsion
}

\author{
Claude Phipps* \\ Photonic Associates, Santa Fe, New Mexico 87505 \\ and \\ James Luke \\ University of New Mexico, Albuquerque, New Mexico 87106
}

\begin{abstract}
We developed an entirely new type of orientation thruster for micro- and nanosatellites. The laser plasma thruster is based on the recent commercial availability of diode lasers with sufficient brightness and $100 \%$ duty cycle to produce a repetitively pulsed or continuous vapor or plasma jet on a surface in vacuum. A low-voltage semiconductor switch can drive the laser. A lens focuses the laser diode output on the ablation target, producing a miniature jet that provides the thrust. Single-impulse dynamic range is nearly five orders of magnitude, and the minimum impulse bit is $1 \mathrm{nN} / \mathrm{s}$ in a 100- $\mu$ s pulse. Even with diffraction-limited focusing optics, at least $0.5-\mathrm{W}$ optical power is needed to produce thrust from selected ablator materials. Thrust-to-power ratio $C_{m}$ is 50 to $100 \mu \mathrm{N} / \mathrm{W}$ and specific impulse $I_{\mathrm{sp}}$ is 200-500 s with a 1-W laser, depending partially on the illumination mode. Transmission and reflection (R) illumination modes are discussed. $R$ mode gives about $50 \%$ better $I_{\mathrm{sp}}$ and two times better $C_{m}$. Improved results are anticipated from higher laser power in the reflection mode. The prototype engine we are developing is intended to provide lifetime on-orbit steering for a 5-kg satellite, as well as reentering it from low Earth orbit.
\end{abstract}

\section{Nomenclature}

$A=$ area of output facet

$B=$ beam brightness, $\mathrm{Wm}^{-2}$ sterrad $^{-1}$

$C_{m}=$ laser momentum coupling coefficient, $\mathrm{N} / \mathrm{W}$

$d=$ diameter of pendulum fiber

$d_{s}=$ diameter of laser spot on target

$d_{0}=$ beam waist diameter (minimum laser spot diameter)

$F \quad=$ thrust, $\mathrm{N}$

$F_{1}=$ torsional pendulum force

$F_{2}=$ calibrating pendulum force

$G=$ torsion modulus of pendulum fiber

$g=$ acceleration of gravity on Earth's surface $\left(9.8 \mathrm{~m} / \mathrm{s}^{2}\right)$

$I \quad=$ moment of inertia of torsion pendulum

$I_{\mathrm{sp}}=$ specific impulse, $\mathrm{s}$

$J=$ polar moment of inertia of pendulum fiber

$k=$ torsional spring constant

$L=$ effective length of pendulum fiber

$L_{t} \quad=$ effective length of calibrating pendulum

$M \quad=$ initial ablatant mass

$m \quad=$ effective mass of torsion pendulum

$P \quad=$ incident laser power, $\mathrm{W}$

$p \quad=$ impulse, $\mathrm{N}-\mathrm{s}$

$Q^{*} \quad=$ laser energy required to ablate $1 \mathrm{~kg}$

$R \quad=$ effective radius of torsion pendulum

$v_{E}=$ exhaust velocity, $\mathrm{m} / \mathrm{s}$

$W \quad=$ incident laser pulse energy

$x_{1}=$ displacement of torsion pendulum

$x_{2}=$ displacement of calibrating pendulum

$x_{\mathrm{th}}=$ thermal penetration depth

$\Delta m=$ ablated mass

Received 7 August 2000; revision received 10 June 2001; accepted for publication 29 June 2001. Copyright (C) 2001 by Photonic Associates. Published by the American Institute of Aeronautics and Astronautics, Inc., with permission. Copies of this paper may be made for personal or internal use, ee to the Copyrigh Clearance Center, Inc., 222 Rosewood Drive, Danvers, MA 01923; include the code 0001-1452/02 \$10.00 in correspondence with the CCC.

*President, 200A Ojo de la Vaca Road; CRPhipps@aol.com. Member AIAA.

${ }^{\dagger}$ Research Assistant Professor, Engineering Research Institute, 901 University Boulevard, SE. Member AIAA.

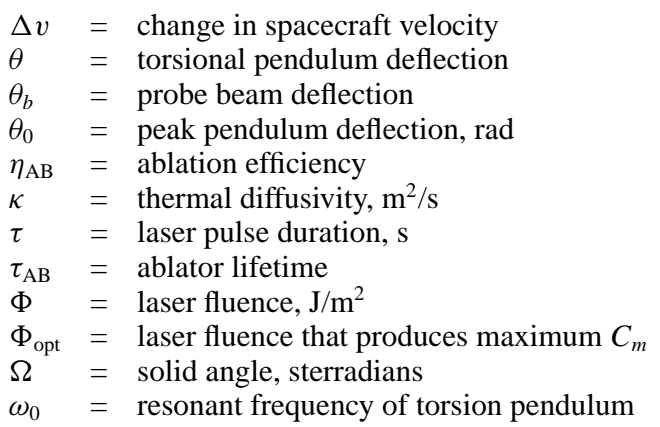

\section{Introduction: Need for a New Microthruster}

T HROUGHOUT most of the history of space propulsion, the 1 emphasis has been on producing rocket engines with ever larger thrust. Now, with the advent of microsatellites $(>10 \mathrm{~kg})$, nanosatellites $(1-10 \mathrm{~kg})$, and even picosatellites $(<1 \mathrm{~kg})$ this trend is reversing in one branch of motor development. Desirable features of such an engine are thrust per axis $100 \mu \mathrm{N}$; less than 1-kg dry weight; size of order $2 \times 10 \times 12 \mathrm{~cm}$; specific impulse of order $500 \mathrm{~s}$; singleimpulse dynamic range 10,000:1; continuous or impulsive thrust; zero off-state power; low-voltage operation; no nozzle; and inexpensive fuel materials and components.

Recent developments in high-brightness diode lasers have been dramatic. The focused intensity available with these devices suggests that a laser-diode-driven plasma jet is possible and represents a way of achieving the preceding features. Figure 1 shows how the engine would work in reflection (R) and transmission (T) mode.

We are developing a prototype engine with which we intend to demonstrate the features just listed. We have demonstrated that all of these features are individually feasible, and it is the purpose of this paper to report the results of our research program. Features we have demonstrated and report here include continuous operation, very large single-impulse dynamic range, good $I_{\mathrm{sp}}$, and excellent thrustto-power ratio. We believe that the laser plasma thruster (LPT) will prove an attractive alternative to the micropulsed plasma thruster.

\section{Laser Diode Capabilities}

Recently, high-brightness diode lasers ${ }^{1}$ have become available with optical power up to $4 \mathrm{~W}$ from a single $100 \times 1 \mu \mathrm{m}$ facet, electrical efficiency in excess of 50\%, 100\% duty cycle, and operating 


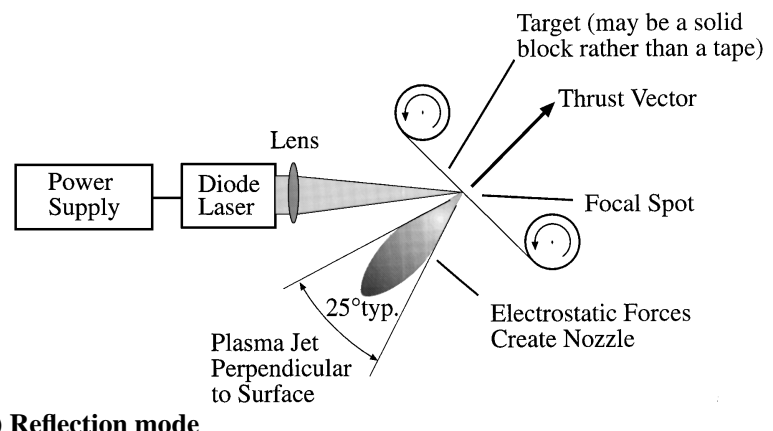

a) Reflection mode

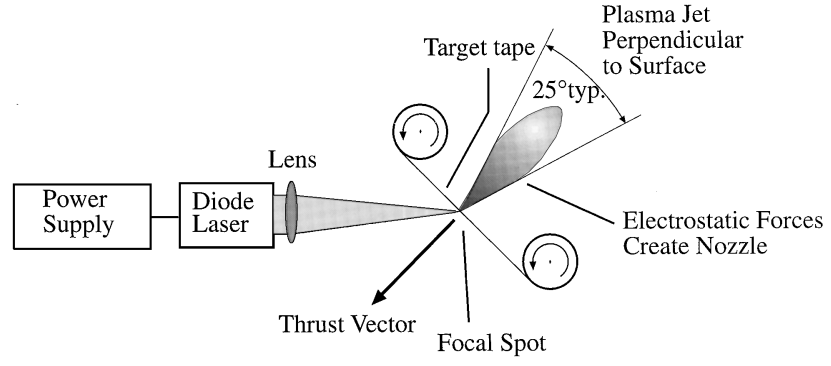

b) Transmission mode

Fig. 1 Schematic diagram of the LPT, contrasting $R$ and $T$ mode of target illumination. R-mode advantages are improved $I_{\mathrm{sp}}$ and $C_{m}$ whereas T-mode advantages are protection of optics from ablation debris.

case temperature up to $95^{\circ} \mathrm{C}$. Mean time between failures is 100,000 $\mathrm{h}$ at $40^{\circ} \mathrm{C}$ (Osinski, J., private communication, SDL, Inc., San Jose CA, May 2001).

A diffraction-limited, 1-W flare-type single-transverse-mode diode at $935-\mathrm{nm}$ wavelength potentially achieves brightness $B=$ $P / \lambda^{2}=1 \mathrm{TWm}^{-2}$ sterrad $^{-1}$. In practice, they can easily be focused to 5 - $\mu$ m-diam spots with $f / 2$ optics to produce $50-\mathrm{GW} / \mathrm{m}^{2}$ intensity on target.

Even the less-bright multi-transverse-mode diodes with emitter effective area $A=100 \mu \mathrm{m}^{2}[100 \mu \mathrm{m}$ long $\times$ one wavelength effective width] typically emit $80 \%$ of their output into $\Omega=0.07$ sterradians, giving $B=0.8 P /(A \Omega) \approx 0.5 \mathrm{TW} \mathrm{m}^{-2}$ sterrad $^{-1}$ for the $4-\mathrm{W}$ Model 6380-A device made by SDL, Inc. (Osinski, private communication). In practice, these can readily be focused with $0.65 \mathrm{NA}$ (numerical aperture) [less than $f / 1$ ] optics to produce a $400-500$ $\mu \mathrm{m}^{2}$ spot, giving $10 \mathrm{GW} / \mathrm{m}^{2}$ on target. As we will show, these intensities are sufficient to form plasma on absorbing materials. Diodes are constant-power (nonstorage) devices.

\section{Plasma Formation with Diodes}

Laser ablation ${ }^{2}$ is the process by which a laser heats a solid surface sufficiently to eject atoms from the surface. This process is complex, covers a wide range of parameters and can involve "phase explosion," 3 as well as vapor production and plasma formation in the vapor immediately above the surface.

Laser impulse production by pulsed-laser-induced ablation in vacuum is well understood..$^{4,5}$ The maximum momentum per joule of incident laser light is produced at a fluence $\Phi_{\text {opt }}$, which is at or just beyond the threshold for plasma formation, because plasma inhibits coupling. Even with laser spot size $d_{s}$ as small as $5 \mu \mathrm{m}$ impulse coupling efficiency $C_{m}$ and the fluence $\Phi_{\text {opt }}$ at which it occurs are well-predicted. Apart from slowly varying factors related to dimensionality of the expansion and the ratio of $d_{s}$ to thermal penetration depth during the pulse, estimates based on the large existing literature for centimeter scale interactions will apply.

To estimate the fluence required to produce plasma jets on a surface, we surveyed the literature in which the fluence for optimum coupling and plasma formation were reported. These are summarized in Fig. 2 (Refs. 5-21).

Figure 2 predicts that diodes with pulse durations at least 0.2 $1 \mathrm{~ms}$ will be able to produce plasma jets. However, for most of these data thermal diffusivity $\kappa$ could be ignored, i.e., the ratio of $x_{\mathrm{th}}=(\kappa \tau)^{1 / 2}$ to laser spot diameter $d_{s}$ was $\ll 1$, either because
Table 1 Figure of merit for selecting target materials is the ratio $x_{\text {th }} / d_{s}$ of thermal diffusion distance during $100 \mu \mathrm{s}$ to $d_{s}=5 \mu \mathrm{m}$. The figure of merit is shown for

\begin{tabular}{lcc}
\multicolumn{3}{c}{ several materials ${ }^{\mathbf{2 2}} \mathbf{2 4}$} \\
\hline \hline Material & $X_{\mathrm{th}}(100 \mu \mathrm{s})$ & $X_{\mathrm{th}} / d_{s}$ \\
\hline PMMA & $1.1 \mu \mathrm{m}$ & 0.22 \\
Polyvinylchloride & $3.1 \mu \mathrm{m}$ & 0.62 \\
Silica & $9.2 \mu \mathrm{m}$ & 1.7 \\
Nylon & 29 & 5.6 \\
Carbon phenolic & $40 \mu \mathrm{m}$ & 8.0 \\
Tungsten carbide & $50 \mu \mathrm{m}$ & 9.9 \\
Aluminum & 88 & 1.7 \\
Copper & $110 \mu \mathrm{m}$ & 21 \\
Graphite & $130 \mu \mathrm{m}$ & 25 \\
\hline \hline
\end{tabular}

of large spots, short pulses, or both. Table 1 (Refs. 22-24) gives this ratio for several materials and indicates that 2-20 times greater fluence than the Fig. 2 values will be required to compensate thermal conductance with our very small spots and relatively long pulses in highly conductive materials where the figure of merit $x_{\mathrm{th}} / d_{s} \geq 1$. This is what we found.

For example, we were not able to produce a spark on aluminum. With $1-\mathrm{W}$ laser power in our research setup $(0.66 \mathrm{~W}$ actually delivered to the surface), it was necessary to use ablatants with low thermal conductivity such as polyvinylchloride (PVC).

\section{Laser Impulse Coupling Physics}

The momentum coupling coefficient $C_{m}$ is defined as the ratio of target momentum $m \Delta v$ produced to incident laser pulse energy $W$ during the ejection of laser-ablated material (the photoablation process). For continuous lasers it is the ratio of thrust $F$ to incident power $P$ :

$$
C_{m}=m \Delta v / W=F / P
$$

In the ablation process $Q^{*}$ joules of laser light (the asterisk is customary notation: $Q^{*}$ is not a complex number) are consumed to ablate each gram of target material:

$$
Q^{*}=W / \Delta m
$$

For the sake of discussion, we will consider a monoenergetic exhaust stream with velocity $v_{E}$. Momentum conservation requires

$$
m \Delta v=\Delta m v_{E}
$$

so that the product of $C_{m}$ and $Q^{*}$ is the effective exhaust velocity $v_{E}$ of the laser rocket, independent of the efficiency with which laser energy is absorbed. This can be seen by writing

$$
C_{m} Q^{*}=\frac{(\mathrm{N}-\mathrm{s})(\mathrm{J})}{(\mathrm{J})(\mathrm{kg})}=\frac{(\mathrm{kg})(\mathrm{m})}{(\mathrm{kg})(\mathrm{s})}=\mathrm{m} / \mathrm{s}
$$

If, for example, a significant amount of the incident energy is absorbed as heat in the target substrate rather than producing material ejection, $Q^{*}$ will be higher, and $C_{m}$ will be proportionately lower, giving the same velocity in the end.

Although it is understood that real exhaust streams have velocity distributions, we have shown ${ }^{25}$ that the monoenergetic stream approximation will not introduce large errors $\left(\left\langle v^{2}\right\rangle /\langle v\rangle^{2} \approx 1.15\right)$ for laser-produced plasmas, and the principal points we want to make will be easier to understand using that assumption.

The specific impulse $I_{\mathrm{sp}}$ is simply related to the velocity $v_{E}$ by the acceleration of gravity:

$$
C_{m} Q^{*}=v_{E}=g I_{\mathrm{sp}}
$$

Energy conservation prevents $C_{m}$ and $Q^{*}$ from being arbitrary. Increasing one decreases the other. Using Eqs. (1) and (2), energy conservation requires that several constant product relationships exist:

$$
2 \eta_{\mathrm{AB}}=\Delta m v_{E}^{2} / W=C_{m}^{2} Q^{*}=g C_{m} I_{\mathrm{sp}}=C_{m} v_{E}
$$




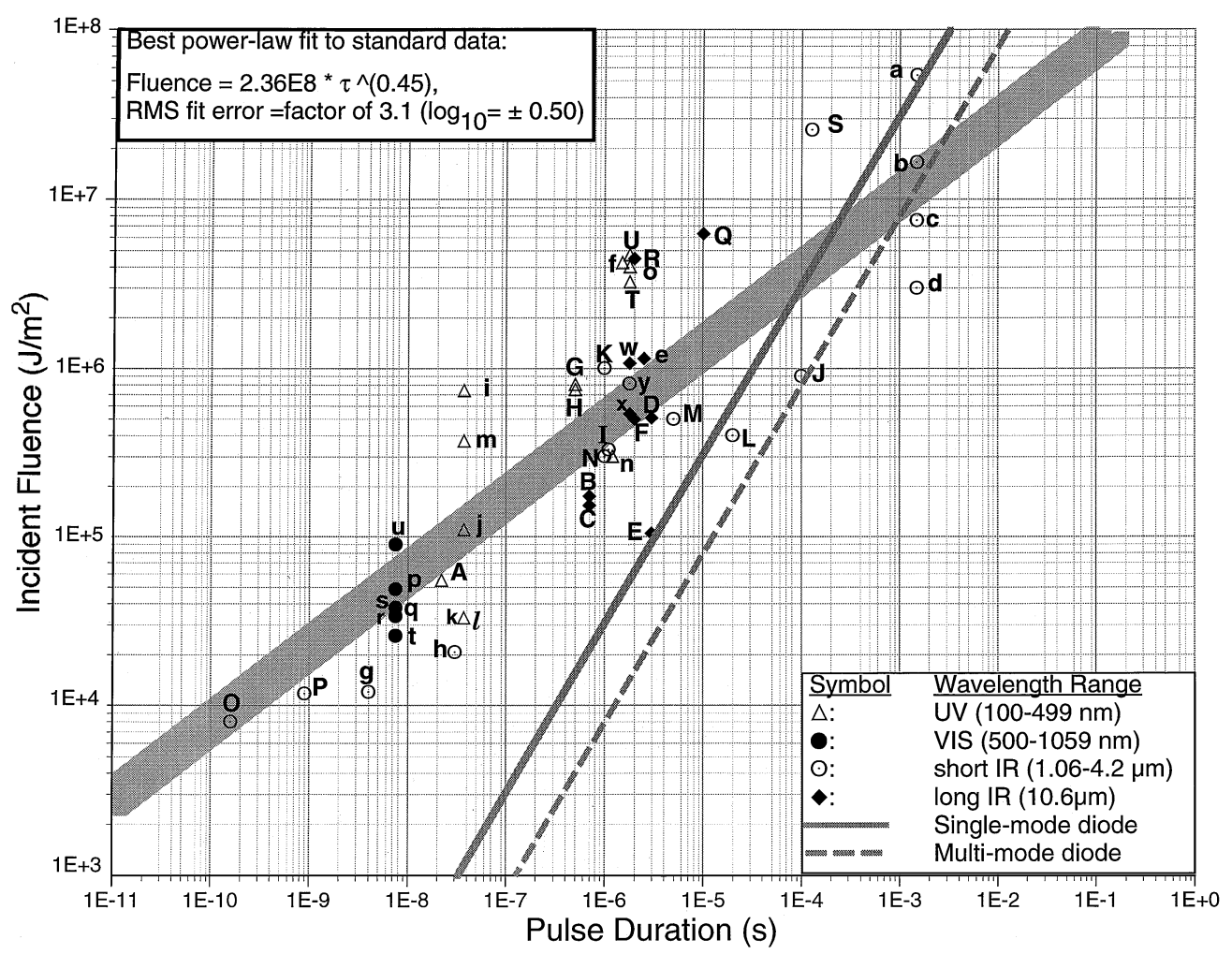

Fig. 2 Fluence required to be incident on the target vs pulse duration for peak coupling and plasma formation from 46 data sets reported in the literature for which peak coupling was recorded. The broad gray bar $\Phi=A \tau^{B}$ with $A=2.38 \mathrm{E} 4$ and $B=0.45$ represents the best fit to the data. Thermal theory gives $B=0.50$. Wavelengths for the data are indicated in the box in the lower-right-hand corner. The solid gray line is the fluence produced by a $0.66-\mathrm{W}$, single-transverse-mode diode with $5-\mu \mathrm{m}$ spot size. The dashed gray line is fluence produced by a 4 -W multimode diode imaged to a $5 \times 100 \mu \mathrm{m}$ spot on target using fast aspheric optics. The indication is that either one can produce a plasma and achieve $\Phi$ opt with pulses longer than 0.2-1 ms. The minority of experiments reported in the literature for which the peak momentum coupling fluence $\Phi_{\text {opt }}$ was measured or can be deduced 0.2-1 ms. The minority of experiments reported in the literature for which the peak momentum coupling fluence $\Phi_{\text {opt }}$ was measured or can be deduced
give the 46 data points shown. Representing lasers with wavelength from $248 \mathrm{~nm}$ to $10.6 \mu \mathrm{m}$ and pulse durations 300 fs $<\tau<1 \mathrm{~ms}$ acting on metals and nonmetals, they follow a trend (the gray bar) to within an rms fit error of a factor of 3 at any given pulse duration. References corresponding to the points are as follows: a, b, c, d: aluminum, copper, graphite, and lead, Ref. 6; e: bismuth, Ref. 7; f: aluminum, Ref. 8; g, h, O, P: aluminum, Ref. 9; i, k, l, m: tantalum, titanium, PMMA, and aluminum (see Ref. 10, pp. 213-234); n: aluminum, Ref. 11; o: aluminum (see Ref. 10, pp. 211, 212); p, q, r, s, t, u: beryllium, graphite, aluminum, zinc, silver, and tungsten, Ref. 12; w, x, A: aluminum, kevlar epoxy, and nylon, Ref. 5; y: kevlar epoxy (see Ref. 10); z: copper, Ref. 13; B, C: cellulose acetate, Ref. 14; E, F: carbon phenolic and graphite, Ref. 15; G: titanium, Ref. 16; H: aluminum,

Ref. 17; I, J, K, L, M: titanium and grafoil, Ref. 18; Q: aluminum, Ref. 19; R: stainless steel, Ref. 20; S: aluminum, Ref. 21; and T, U: aluminum (see Ref. 10, pp. 199-202).

In Eq. (6) we introduce the ablation efficiency parameter $\eta_{\mathrm{AB}} \leq 1$, the efficiency with which laser energy $W$ is converted into exhaus kinetic energy. Choosing combinations of $C_{m}$ and $v_{E}$ that exceed 2 violates physics because $\eta_{\mathrm{AB}}$ must be less than 1 .

Because the maximum specific impulse of ordinary chemical rockets is about $500 \mathrm{~s}$, limited by the temperatures available in chemical reactions, exit velocity $v_{E}>5 \mathrm{~km} / \mathrm{s}\left(I_{\mathrm{sp}}>500 \mathrm{~s}\right)$ is accessible only by laser ablation or some other nonchemical process such as ion drives.

Ablation efficiency can approach $100 \%$, as direct measurements with other types of lasers on cellulose nitrate in vacuum verify, ${ }^{5}$ but a value of $50 \%$ or even less is likely. The impact of $\eta_{\mathrm{AB}}<1$ is that the $C_{m}$ value deduced from a given $v_{E}$ might be less than the maximum permitted by conservation of energy. Exit velocity $v_{E}$ is the fundamental quantity.

Some of the factors that affect ablator lifetime are shown in Eq. (7), where the final term emphasizes the crucial importance of $I_{\mathrm{sp}}$ :

$$
\tau_{\mathrm{AB}}=|M / \dot{m}|=M g I_{\mathrm{sp}} / F
$$

In Eq. (7) $M$ is the initial ablatant mass, and $\dot{m}$ is the mass ablation rate. The vacuum coupling coefficient $C_{m}$ is in the range $10-100 \mu \mathrm{N} / \mathrm{W}$ for many standard surface-absorbing materials. ${ }^{4}$

Purpose

\section{Experiments}

The purpose of our research program was to determine what materials give good $I_{\mathrm{sp}}$ and suitable $C_{m}$ for a microthruster when illuminated by focused laser diodes.
Torsion Balance

To measure impulses five orders of magnitude upward from nanoNewtons/second, we constructed a highly sensitive torsion pendulum (Figs. 3 and 4). Although this fact is not specifically relevant to our measurement program, the sensitivity of the pendulum is illustrated by the fact that it readily responded to the pressure (not ablation pressure) of $1 \mathrm{~W}$ of laser light.

\section{Torsion Balance Operation}

The pendulum deflection $\theta$ is evaluated by reflecting a probe laser off a micromirror mounted to the center of the torsion mechanism (Fig. 3), and pendulum rotation

$$
\theta=\theta_{b} / 2
$$

is half the probe beam deflection (Fig. 5). The method for measuring $\theta_{b}$ is discussed in the section "Experimental Setup." Torque $M$ defines the constant $k$ :

$$
\begin{gathered}
M=F R=k \theta \\
k=G J / L \\
1 / L=1 / L_{1}+1 / L_{2} \\
J=\pi d^{4} / 32
\end{gathered}
$$

Equating kinetic and stored energy

$$
W=k \theta_{0}^{2} / 2=p^{2} / 2 m=I \omega_{0}^{2} \theta_{0}^{2} / 2
$$




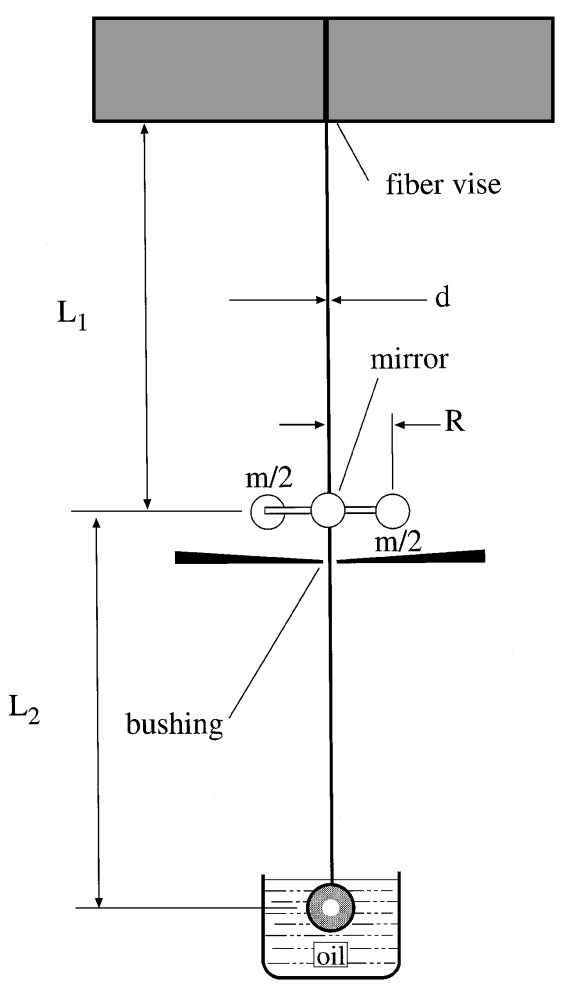

Fig. 3 Two torsion balances were constructed from $d=78 \mu \mathrm{m}$ fused silica fiber to make coarse and fine measurements. These differed mainly in the magnitude of the rotating mass. $L_{1} \approx L_{2} \approx 10 \mathrm{~cm}$. Either position labeled $m / 2$ is equivalent for mounting the target. For the light pendulum the rotating effective mass was $17.3 \mathrm{mg}$ (see Table 3 ). The fiber vise is attached to a stepper motor and 200:1 gearbox, which rotates it in is attached to a stepper motor and 200:1 gearbox, which rotates it in
$300-\mu$ rad steps for precise positioning of the target. Target position is maintained within $\pm 3 \mu \mathrm{m}$ for weeks.

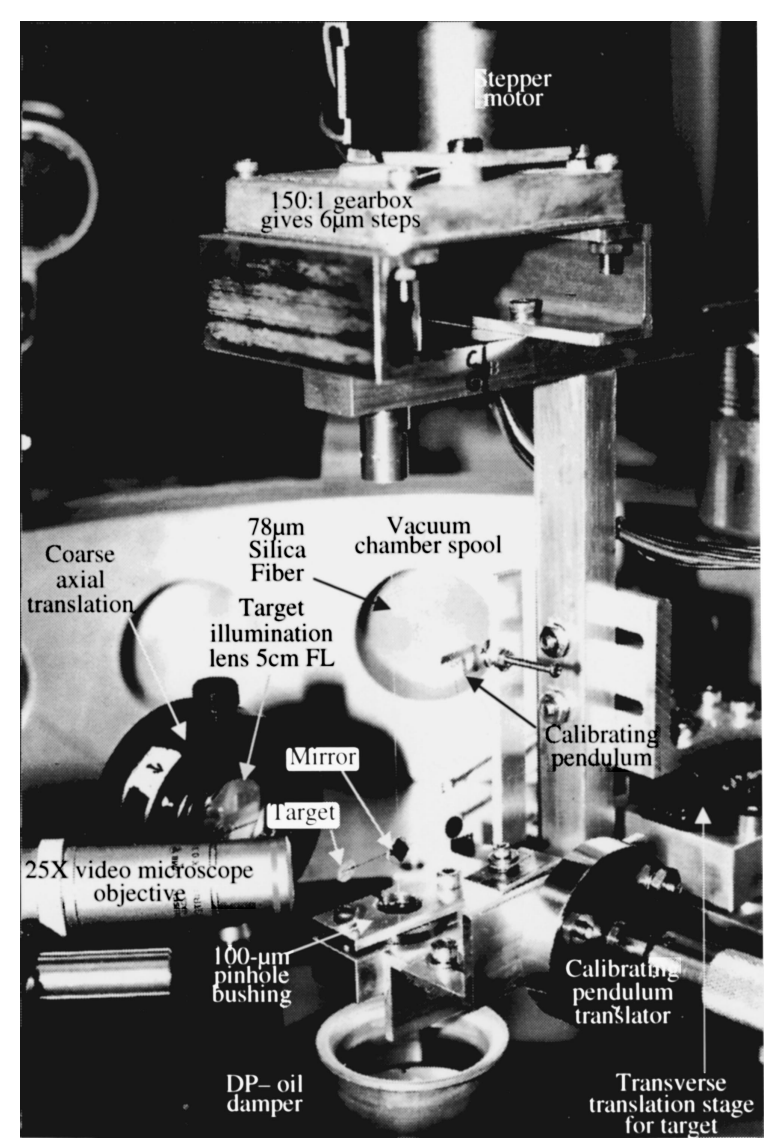

Fig. 4 Torsion pendulum under calibration.

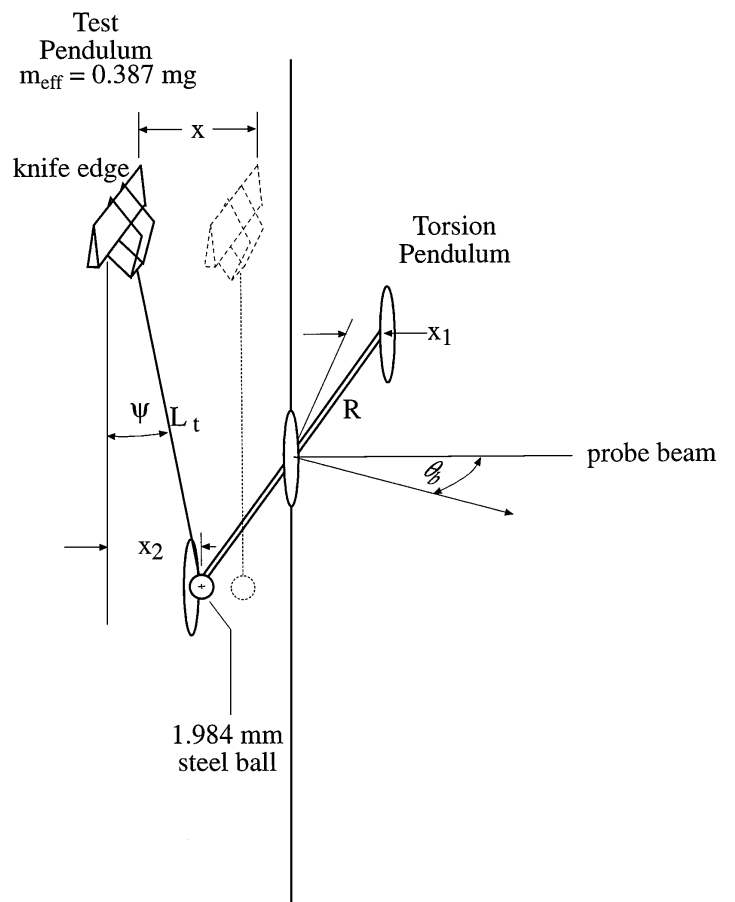

Fig. 5 Force calibration was found to be much more accurate than impact calibration.

gives the resonant frequency

$$
\omega_{0}=\sqrt{k / I}
$$

In the preceding

$$
I=m R^{2}
$$

$\theta_{0}$ is pendulum peak deflection in response to impulse $p$. From Eq. (13) the impulse response of the pendulum is

$$
p / \theta_{0}=\sqrt{k m}=\sqrt{G J m / L}=\sqrt{(\pi G m / 32 L)} d^{2}
$$

and the force response

$$
F / \theta=G J / L R=(\pi G / 32 L R) d^{4}
$$

Torsion Balance Calibration

These relationships suggest four distinct ways of determining the value of the product $G J$ by calibration or direct calculation: From Eq. (14) by observing the resonant frequency of the pendulum and calculating the effective rotating mass,

$$
(G J)_{1}=\operatorname{Lm} R^{2} \omega_{0}^{2}
$$

or, by direct calculation based on tabulated material constants for our $78-\mu \mathrm{m}$-diam fused silica fiber,

$$
(G J)_{2}=\pi d^{4} G / 32=109.0
$$

or, by applying a known force from a standard pendulum and observing the deflection $\theta$

$$
(G J)_{3}=F L R / \theta
$$

or, by applying a known impulse $p$ via a collision with a standard pendulum and observing the deflection amplitude,

$$
(G J)_{4}=p^{2} L / m \theta_{0}^{2}
$$

Of these, method 3 gave by far the most precise result. Method 1 was difficult to do accurately but did provide a useful way to account for varying response caused by small variations in target mass that occur from test to test after calibration. Method 2 is not a direct method. With method 4 accurately measuring the recoil was difficult, and finding materials with the correct coefficient of restitution for zero recoil of the test mass was more difficult. With method 3 the measured variables were simple and static, giving a measurement accuracy better than 5\%. 
Table 2 Pendulum response parameters

\begin{tabular}{lcc}
\hline \hline Pendulum & Light & Heavy \\
\hline Resonant frequency, Hz & 1.73 & 0.33 \\
Effective mass, mg & 17.3 & 580 \\
$L_{1}, \mathrm{~m}$ & 0.10 & 0.10 \\
$L_{2}, \mathrm{~m}$ & 0.070 & 0.10 \\
$p / \theta_{0}, \mu \mathrm{N}-\mathrm{s} / \mathrm{rad}$ & $6.81 \pm 4 \%$ & $35.8 \pm 4 \%$ \\
$F / \theta, \mu \mathrm{N} / \mathrm{rad}$ & $134 \pm 4 \%$ & $110.4 \pm 4 \%$ \\
Resolution, pN-s & 200 & 1000 \\
Capacity, $\mu \mathrm{N}-\mathrm{s}$ & $4.0 \pm 4 \%$ & $20 \pm 4 \%$ \\
\hline
\end{tabular}

To do the calibration, it was necessary to take account of the fact that both pendula move when the test pendulum is advanced a distance $x$ via a micrometer stage. Because $x$ was the measured variable, it was never necessary to measure the angle $\Psi$. We have

$$
\begin{gathered}
x=x_{1}+x_{2} \\
F_{1}=\frac{G J \theta \cos \theta}{L R} \approx \frac{G J x_{1}}{L R^{2}} \\
F_{2}=m_{\mathrm{eff}} g \tan \Psi \approx \frac{m_{\mathrm{eff}} g x_{2}}{L_{t}} \\
G J\left(\frac{L R^{2}}{G J}+\frac{L_{t}}{m_{\mathrm{eff}} g}\right) \approx \frac{2 R L x}{\theta_{b}}
\end{gathered}
$$

The approximation in Eq. (23) was accounted for by using small displacements. Friction hysteresis was accounted for by comparing measurement series with $x$ increasing vs $x$ decreasing and eliminating displacements large enough to cause hysteresis outside the desired measurement accuracy.

This simple method resulted in the calibration data shown Table 2. The value for $G J=(G J)_{3}$ obtained from the calibration agreed with the calculated value $(G J)_{2}$ to within $1 \%$. Given an accurate value for $G J$, what is ultimately desired, of course, is the momentum coupling coefficient $C_{m}$ :

$$
C_{m}=\left(p / \theta_{0}\right)\left(\theta_{0} / W\right)
$$

where $\theta_{b}=2 \theta_{0}$ and $W$ are the measured quantities.

\section{Time-Average Fluence}

With the lightweight pendulum and to a much smaller extent with the heavy one, target acceleration leads to substantial target motion during the longer laser pulses. This leads to time-varying fluence, a situation we want to avoid. It was important to be able to correct data when this variation was slight, as well to indicate when it was necessary to switch to the heavy pendulum to get a meaningful measurement. Further, in about half the shots we deliberately chose $d_{s} \gg d_{0}$, say $100 \mu \mathrm{m}$ instead of $5 \mu \mathrm{m}$, to obtain data for coupling for a range of fluence as well to anticipate coupling with multimode diodes. With so many variables we needed an analytical method of determining the fluence variation during a pulse. Taking

$$
\begin{gathered}
\langle\Phi\rangle=\frac{1}{\tau} \int_{0}^{\tau} \mathrm{d} t \Phi(t)=\frac{4 W_{L}}{\pi \tau} \int_{0}^{\tau} \frac{\mathrm{d} t}{\mathrm{~d}^{2}(t)} \\
\mathrm{d}^{2}(t)=d_{0}^{2}+\left(\sqrt{d_{s}^{2}-d_{0}^{2}}+\frac{z}{f_{\#}}\right)^{2}
\end{gathered}
$$

with

$$
d_{1}=\sqrt{d_{s}^{2}-d_{0}^{2}}
$$

we have (please refer to Fig. 6)

$$
\begin{aligned}
\langle\Phi\rangle & =\frac{4 W_{L} f_{\#}^{2}}{\pi \tau} \int_{0}^{\tau} \frac{\mathrm{d} t}{\left(f_{\#} d_{1}+z\right)^{2}+\left(f_{\#} d_{0}\right)^{2}} \\
& =C \int_{0}^{\tau} \frac{\mathrm{d} t}{\left(\alpha+\beta t^{2}\right)^{2}+\gamma^{2}}
\end{aligned}
$$

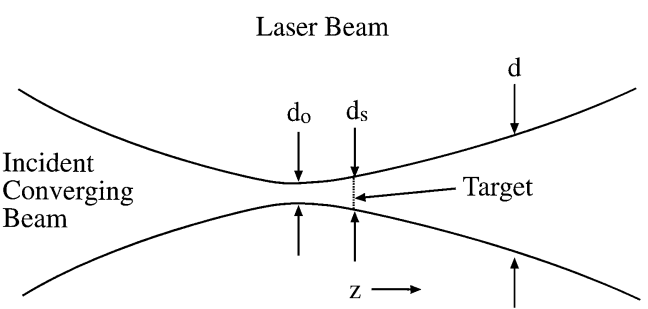

Fig. 6 Illustrating parameters near focus.

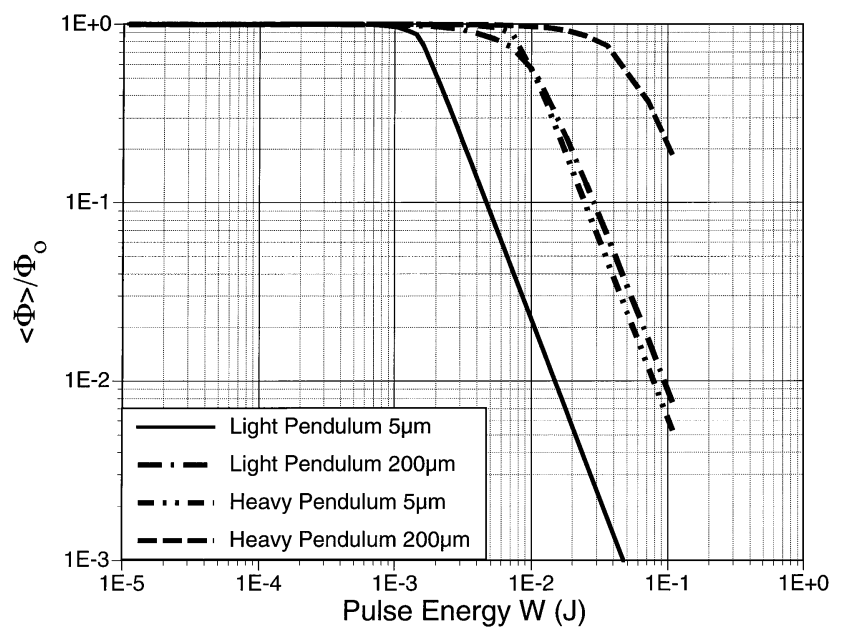

Fig. 7 Ratio of time average to peak fluence for light and heavy pendula vs pulsewidth, showing the effect of pendulum motion during the pulse [see Eq. (30) of text].

where

$$
\begin{array}{lrr}
C=\frac{4 W_{L} f_{\#}^{2}}{\pi \tau}, & \gamma=f_{\#} d_{0}, & \alpha=f_{\#} d_{1} \\
\beta=\frac{\omega_{0} \theta_{0} R}{2 \tau}, & z=\frac{\ddot{z} t^{2}}{2}, & \ddot{z}=\frac{\omega_{0} \theta_{0} R}{\tau}
\end{array}
$$

The integral (30) is tabulated, ${ }^{26}$ and the result is

$$
\begin{aligned}
\langle\Phi\rangle & =\frac{C}{4 \beta^{2} q^{3} \sin \psi} *\left\{\sin \left(\frac{\psi}{2}\right) \ln \left[\frac{t^{2}+2 q t \cos (\psi / 2)+q^{2}}{t^{2}-2 q t \cos (\psi / 2)+q^{2}}\right]\right. \\
& \left.+2 \cos \left(\frac{\psi}{2}\right) \tan ^{-1}\left[\frac{t^{2}-q^{2}}{2 q t \sin (\psi / 2)}\right]\right\}\left.\right|_{0} ^{\tau}
\end{aligned}
$$

with

$$
q^{2}=\frac{\sqrt{\alpha^{2}+\gamma^{2}}}{\beta}, \quad \Psi=\cos ^{-1}\left[\frac{-1}{\sqrt{1+(\gamma / \alpha)^{2}}}\right]
$$

Figure 7 shows how time-average fluence varies with pulse width using Eq. (30) and experimental parameters. The bottom line is that the heavy pendulum must be used for pulse energy $W>1 \mathrm{~mJ}(5-\mu \mathrm{m}$ spot) or $W>10 \mathrm{~mJ}(200-\mu \mathrm{m}$ spot). Even with the heavy pendulum and $200-\mu \mathrm{m}$ focal spot size, results start losing their meaning because of varying spot size around $300 \mathrm{~mJ}$. For this reason we have no data for higher energy.

\section{Experimental Setup}

The diffraction-limited beam from an SDL, Inc., XC30 singlemode research laser was sent through a vacuum chamber window and focused on the target using an axial gradient index lens (Lightpath Technologies, Inc.). This technology yields a relatively inexpensive simple-lens shape, which matches the optical performance of an aspheric (Figs. 8 and 9).

Transition to the vacuum laser momentum coupling regime will be essentially complete at 500 mtorr. That is, the residual gas will make little difference to $C_{m}$ or $I_{\mathrm{sp}}$ at this pressure. We maintained chamber pressure less than 0.3 mtorr. 


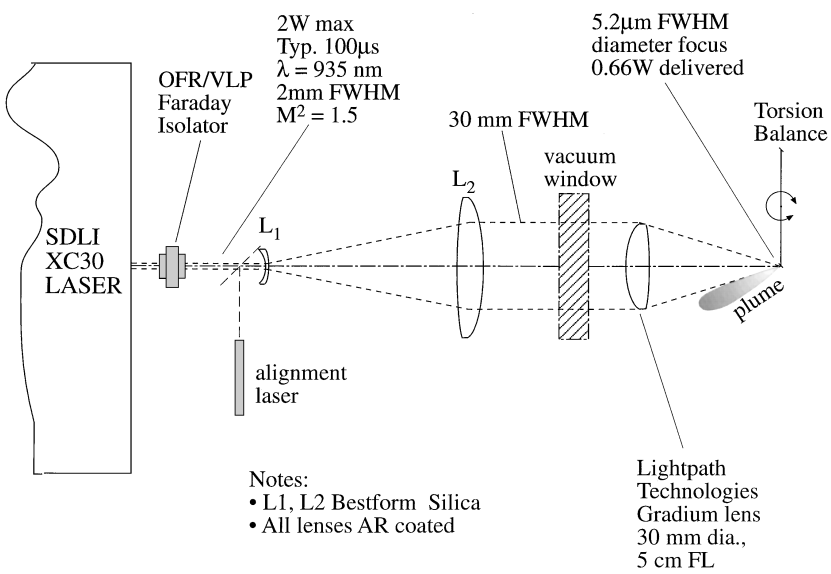

Fig. 8 Schematic of tabletop test setup. The window before the final focusing lens is a vacuum window. Target illumination $N A=0.47$ and spot diameter $d_{s}=5.2 \mu \mathrm{m}$ full width at half-maximum (FWHM). The Faraday isolator prevents backreflections from interfering with singlemode operation of the laser. Beam quality $M^{2}=1.5$ is equivalent to mede operation of the laser. Beam . Pressure in the chamber was typically 0.2 mtorr. No effort was made to attain high vacuum conditions. Pressures less than a few mtorr are sufficient to avoid interfering with plasma formation and expansion.

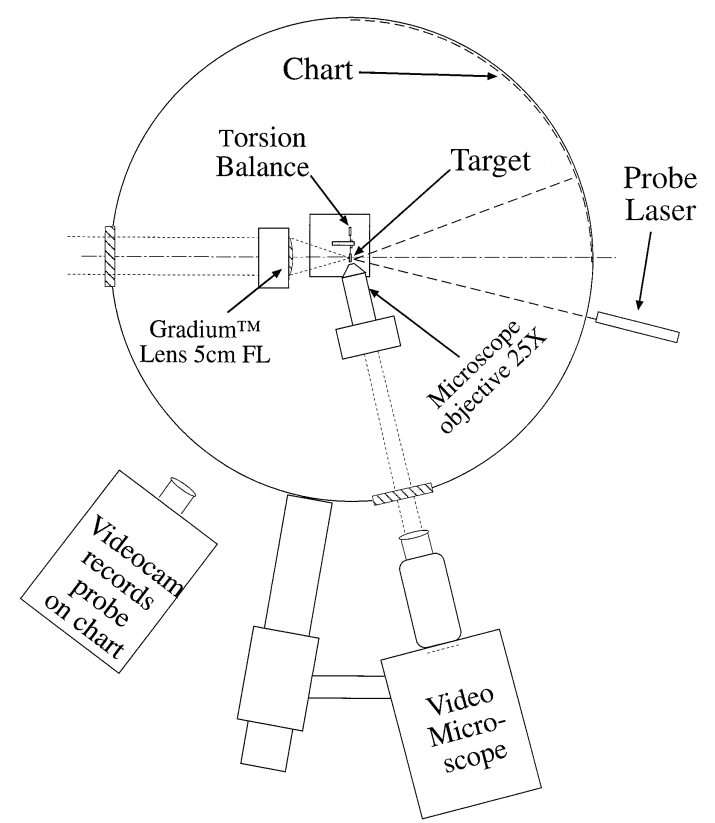

Fig. 9 Plan view of setup inside target chamber. Target position is measured to within $\pm 3 \mu \mathrm{m}$ using the video microscope. Spot size is determined by analyzing the illumination distribution scattered from a fixed planar target, which is substituted for the target. The videocam views the chart through a bell jar, which sits on top of spool shown. Precise axial mith of target was achieved with a 20:1 "leverage" by moving external lens L2 (see Fig. 8) on a translation stage.

Pendulum deflection was determined by reading the maximum deflection $\theta_{b}$ of the probe beam reflected from the mirror at the center of the pendulum onto a ruled chart attached to the inside of the vacuum chamber. This reading was recorded by the video camera/recorder indicated in Fig. 9, and the recordings analyzed frame by frame for maximum deflection at the conclusion of an experiment series. Because the chart was cylindrical in shape, no additional error was associated with reading large vs small deflections. Resolution of the technique was $0.1 \mathrm{~mm}$ at $23.5-\mathrm{cm}$ radius, corresponding to $210 \mu \mathrm{rad}$ of pendulum motion or, for the light pendulum, $1.45 \mathrm{nN} / \mathrm{s}$. A few measurements were made using a 3.4-m optical lever arm (and a chart located outside the chamber), enabling about seven times higher resolution for very small deflections. These gave the $200 \mathrm{pN}-\mathrm{s}$ minimum resolution figure given in Table 2.

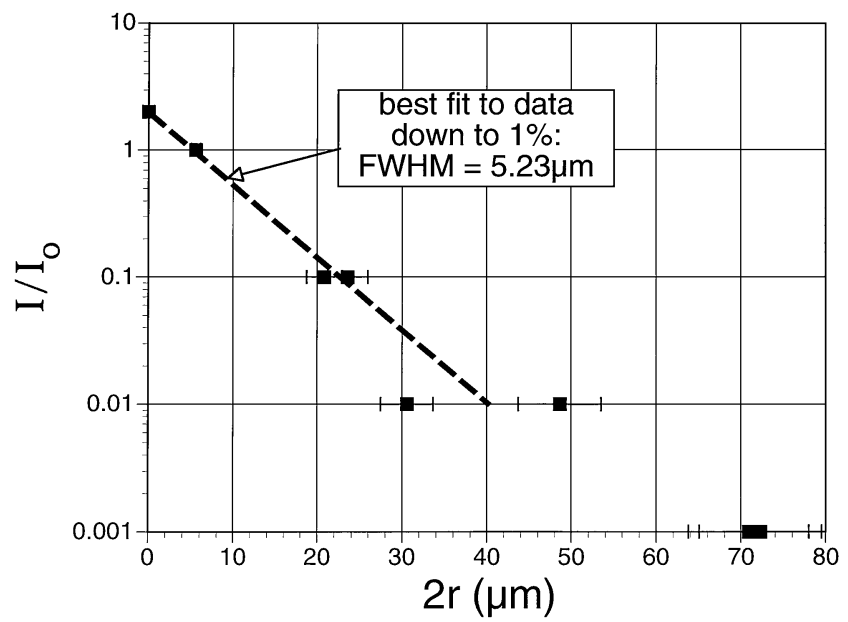

Fig. 10 Best fit to top $99 \%$ of intensity distribution gives spot diameter $d_{s}=5.2 \mu \mathrm{m} \pm 10 \%$ FWHM.

The minimum impulse we observed in any of our measurements was $400 \pm 200 \mathrm{pN}-\mathrm{s}$. A typical measurement series covered 1$15 \mu \mathrm{N}-\mathrm{s}$.

The laser was usually operated at $50 \%$ of maximum output $(1 \mathrm{~W})$ for long life and constant output. Attenuation through the Faraday rotator, lenses, and windows gave $0.66 \mathrm{~W}$ incident on the target with $1-W$ laser output. Figure 10 demonstrates that spot diameter on target was $5 \mu \mathrm{m} \pm 10 \%$.

\section{Results}

A total of 106 single-pulse data sets were taken using the singlemode research laser on materials ranging from black PVC film to black ink on paper, in both $\mathrm{R}$ and $\mathrm{T}$ illumination modes.

About half of these data were taken in R mode with the jet on the same side of the target as the incident light. Other data are instead taken in T mode, the laser beam passing through a transparent, highly damage-resistant substrate film to blow off an absorbing coating on the opposite side. This mode has two important features relative to the $R$ mode: 1) vapor blown off the target cannot cloud the focusing optics and 2) the construction of the thruster itself is simplified.

Optics contamination was a minor problem in the approximately 2000 individual shots taken in our research program. However, for the much longer exposure expected in the prototype thruster's lifetime keeping the optics clear will require more effort. T-mode illumination is an effort to address this problem.

We mainly used polyethylterephthalate (PET) and Kapton ${ }^{\mathrm{TM}}$ polyimide resin film, 100-125 $\mu$ m thick, for T-mode measurements.

Black PVC film gave the best consistent results for $C_{m}$ and $I_{\mathrm{sp}}$ of any ablatant we tested. Black polymethylmethacrylate (PMMA) also gave good results but did so less consistently and was more difficult to handle.

Figure 11 shows a typical range of target ablation spots in PVC film. The majority of our single-pulse data was taken with PVC films. Figures 12 and 13 show our R-mode PVC data for $C_{m}$ and $I_{\mathrm{sp}}$ using $5-\mu \mathrm{m}$ spot size. Figures 14 and 15 show T-mode PVC data for both 5- and 100- $\mu \mathrm{m}$ spot size. Scatter is discussed in the following section. Table 3 summarizes data for these and some additional materials. Perhaps most promising among these is the triazene "designer polymer" being developed for us by polymer chemists at the Paul Scherrer Institut. ${ }^{27}$

\section{Measurement Errors}

Standard errors in measuring $C_{m}$ were $\pm 10 \%$ and in measuring $I_{\mathrm{sp}} \pm 25 \%$. For $C_{m}$ these come from the combined uncertainty of measuring pulse energy and pendulum deflection and pendulum calibration error. The latter is $\pm 4 \%$ (Table 2 ), and pendulum deflection error in the range of data reproduced here is $\pm 2 \%$. The remainder of the error is caused by uncertainties in the laser calorimeter response.

For $I_{\mathrm{sp}}$, determined from the product $C_{m} Q^{*}$, measurement uncertainties are those of $C_{m}$ augmented by the larger uncertainties inherent in our measurement of excavated mass leading to $Q^{*}$. 


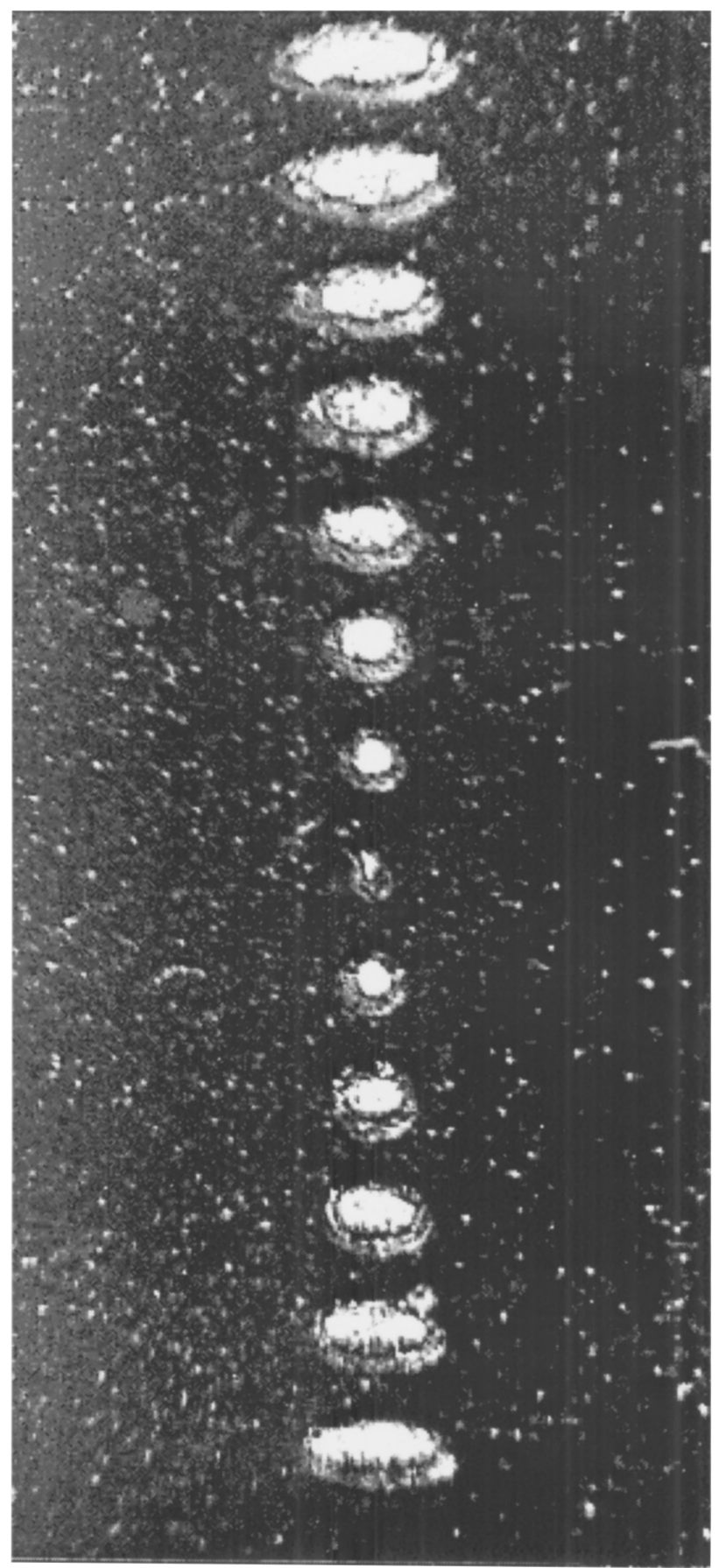

Fig. 11 Photomicrographs of single-pulse target burn spots take while focusing the multimode diode laser range from $425 \times 170 \mu \mathrm{m}$ (top) to $390 \times 125 \mu \mathrm{m}$ (bottom), with best focus at center producing a $100 \times 25 \mu \mathrm{m}$ ablation spot. The illumination distribution that produced this spot (image of diode output facet) is estimated to be $100 \times 5 \mu \mathrm{m}$. High-divergence ("fast") axis of laser is oriented horizontally. Absorbing film was $20 \mu \mathrm{m}$ thick; substrate was $100 \mu \mathrm{m}$ PET.

In all of the single-pulse measurements, ablated mass was on the order of nanograms, and so it was impossible to determine it by weighing the targets. Instead, it was necessary to determine $Q^{*}$ by direct microscopic measurement of the excavated volume. Though we avoided assigning $Q^{*}$ values when the character of the target ablation did not involve clean craters, some uncertainty in the results derives from qualitiative judgment factors. This source of error will be eliminated when long-term continuous operational data from the prototype are available.

\section{Discussion}

Coupling coefficients measured on a planar surface, which is much larger than the illumination spot, will be enhanced (relative to

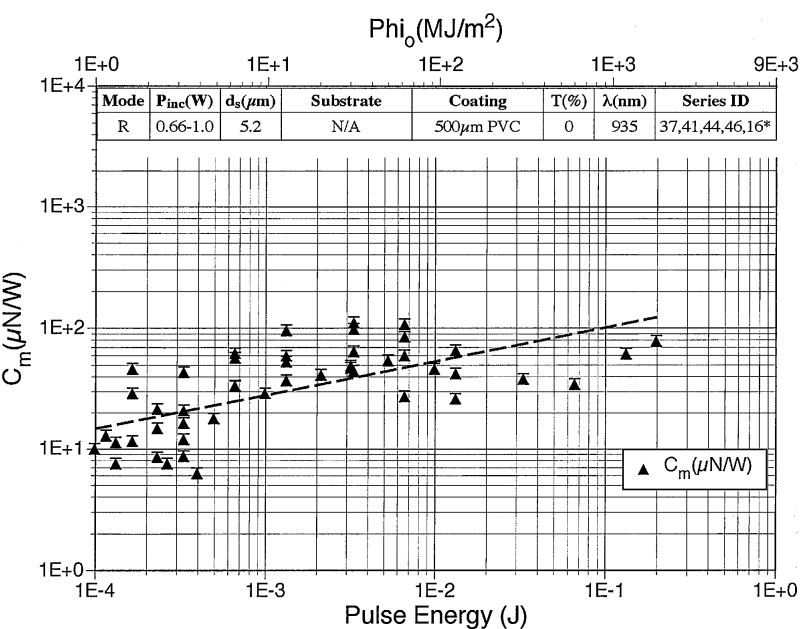

Fig. 12 Combined data from several measurement series showing coupling coefficient for black PVC film, R-mode, 5- $\mu \mathrm{m}$-diam laser spot.

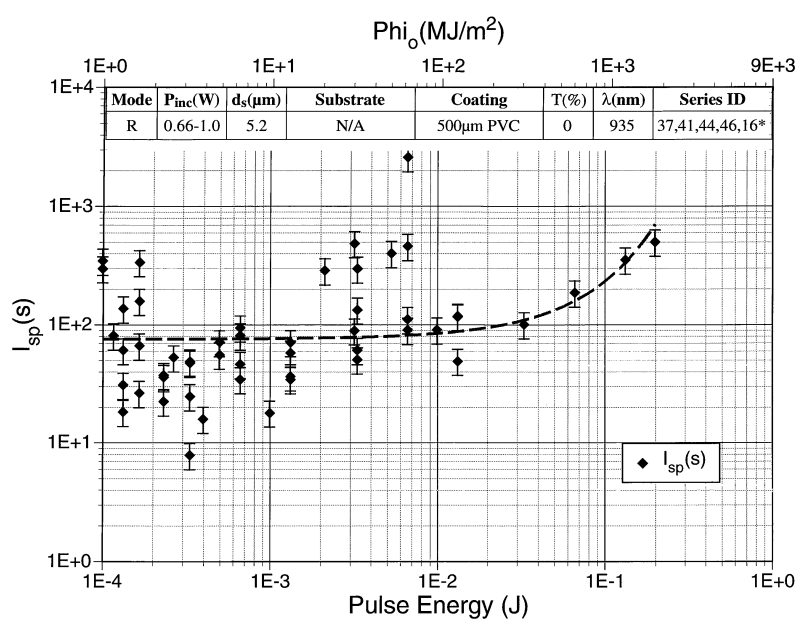

Fig. 13 Combined data from several experiments showing specific impulse, black PVC film, R mode, 5- $\mu \mathrm{m}$ illumination spot.

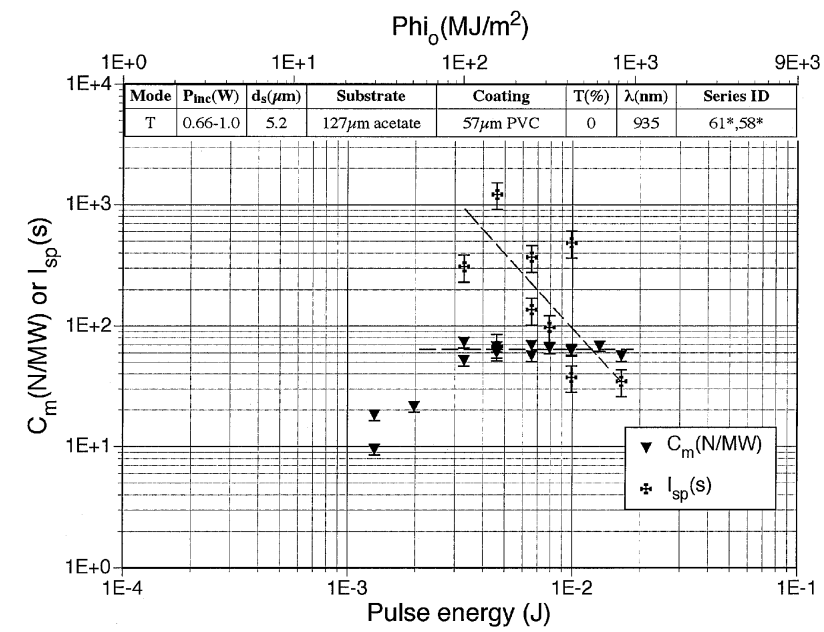

Fig. 14 Coupling coefficient and specific impulse measured with single pulses from the single-mode research laser focused to $5-\mu \mathrm{m}$ spot diameter, on PVC/acetate target in T mode.

comparable literature values) by a large contribution from the initial blast wave as it spreads across this surface. Comparable standard data for carbon-bearing materials ${ }^{18}$ give $C_{m}=45 \mu \mathrm{N} / \mathrm{W}$, about $40 \%$ of what we see.

Scatter in the $C_{m}$ and $I_{\mathrm{sp}}$ data is not accounted for by the error bars associated with the measurement techniques. Scatter was observed to be larger with data taken at $5 \mu \mathrm{m}$ than with 100-200- $\mu \mathrm{m}$ laser spot diameter. We believe the scatter is partly caused by spot-to-spot 
Table 3 Single-pulse data summary

\begin{tabular}{lcccc}
\hline \hline & & & $\begin{array}{c}\text { Peak of } \\
\text { best-fit }\end{array}$ & $\begin{array}{c}\text { Peak of } \\
\text { best-fit } \\
I_{\text {sp }}, \mathrm{s}\end{array}$ \\
Ablatant (substrate) [data series] & Mode & $d_{s}, \mu \mathrm{m}$ & $C_{m}, \mu \mathrm{N} / \mathrm{W}$ & \\
\hline PVC [37, 41, 44, 46, 16*] & $\mathrm{R}$ & 5 & 120 & 650 \\
Printer's ink (paper) [4, 12,30] & $\mathrm{R}$ & 5 & 32 & 200 \\
PVC (PET) [46*] & $\mathrm{T}$ & 100 & 65 & 300 \\
Scherrer triazene polymer & & & & \\
(PET)[23*, 24*] & $\mathrm{T}$ & 5 & 50 & 200 \\
PVC (PET) [44*] & $\mathrm{T}$ & 5 & 45 & 500 \\
\hline
\end{tabular}

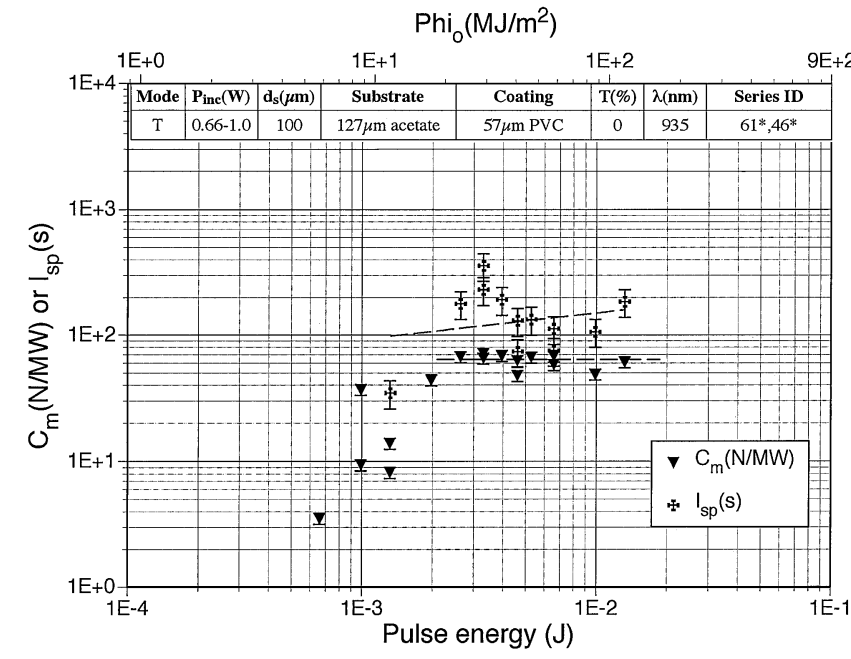

Fig. 15 Coupling coefficient and specific impulse measured with single pulses from the single-mode research laser on PVC/acetate target in T mode. Here, 100- $\mu \mathrm{m}$ spot diameter was used (compare Fig. 14). As expected, $I_{\text {sp }}$ does not reach as large a maximum value.

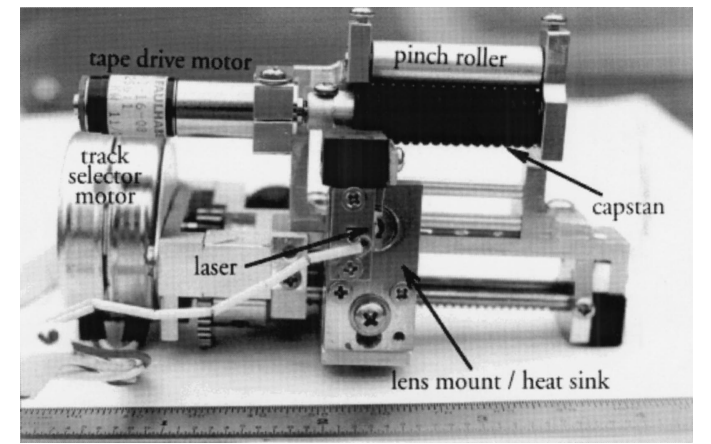

Fig. 16 LPT test assembly prior to insertion in vacuum chamber.

variations of the ablatant physical and chemical properties over a $5-\mu \mathrm{m}$ scale, including granularity effects in the carbon doping material employed to achieve absorbance. These effects will always be more pronounced near ignition threshold (low fluence) than at maximum fluence in any set of data. More weight should be given to the high-fluence than the low-fluence data in any set.

$\mathrm{R}$ mode showed more scatter than $\mathrm{T}$-mode data. We believe that interference of the ejecta with the incident beam might have been responsible. Target granularity is also an important contributing factor to data scatter in both modes.

The trend with R-mode data is for increased $C_{m}$ with increased fluence, opposite to the trend with T-mode data. The main reason for this is that in $\mathrm{R}$ mode the available ablatant was infinite, practically speaking, whereas in T mode a fixed coating thickness was available for coupling to the laser beam. After the material is burned, further increases in fluence can only lead to lower $C_{m}$.

Table 3 shows that $C_{m}$ is reduced by about a factor of two in $\mathrm{T}$ mode, but $I_{\mathrm{sp}}$ stays relatively high. One significant difference for this mode is that its performance is optimized for a relatively narrow pulse duration range. This is because the absorbing surface

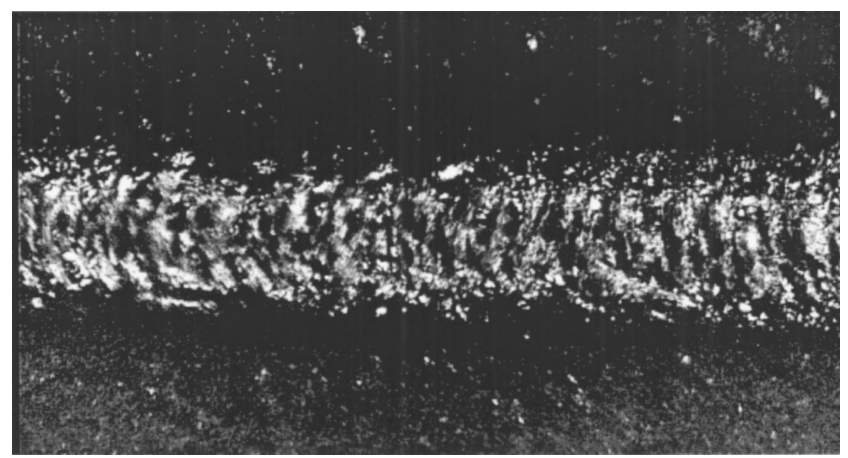

Fig. 17 Continuous track formed with the multimode laser at 0.4-W laser power is $250 \mu \mathrm{m}$ wide. Target speed was $2.8 \mathrm{~mm} / \mathrm{s}$. Picture is of exit surface, front lit.

is heated first at the interface and rapidly blown off. It needs to be thin - not much thicker than one absorption depth; otherwise, most of the ejecta will not be heated, and $I_{\mathrm{sp}}$ will be low, even though $C_{m}$ remains high. In contrast, in the reflection mode the absorbing surface can be arbitrarily thick and still achieve the same $I_{\mathrm{sp}}$ as the laser burns slowly through at the surface recession velocity of a few centimeter per second.

\section{Prototype}

We have mostly finished the impulse data, have selected a preliminary target material, and have done short continuous burns. The next step is development of a continuous thrust experiment, including a continuous loop tape drive, thrust stand, etc., followed by design and testing of a finished prototype configuration. Figure 16 shows construction details, and Fig. 17 shows a track obtained with the continuous thrust setup.

\section{Conclusions}

We demonstrated the feasibility of the laser microthruster concept. Impulse bits as small as $0.4 \mathrm{nN} / \mathrm{s}$ (40 $\mu$ dyn-s) were measured during a $60-\mu$ s pulse. Maximum impulse with our $1-\mathrm{W}$ laser during a 0.3 -s pulse was $20 \mu \mathrm{N}$-s. The range between these extremes is nearly five orders of magnitude.

We measured specific impulse as large as $1000 \mathrm{~s}, 500 \mathrm{~s}$ being typical for pulses longer than $50 \mathrm{~ms}$. Coupling coefficients were as large as $210 \mu \mathrm{N} / \mathrm{W}, 120$ being typical. Exhaust velocity (determined from the product of $C_{m}$ and $Q^{*}$ ) ranged up to $5 \mathrm{~km} / \mathrm{s}$.

We routinely created 5- $\mu \mathrm{m}$ laser spots on targets with low-spotsize jitter. We found spot sizes up to $200 \mu \mathrm{m}$ useful to maximize coupling efficiency by avoiding target burnthrough for longer pulses, as well as to provide more spacially uniform target illumination. To measure such small impulses accurately, we created and accurately calibrated a highly sensitive microbalance. We have obtained a continuous track on our PVC ablatant in transmission mode using a 2-W multimode laser.

\section{Appendix: Further Work}

The largest continuous power available today from a highbrightness, single-facet diode laser is $4 \mathrm{~W}$ (SDLI 6380-A). At $3-\mathrm{mm} / \mathrm{s}$ target translation speed a $5 \times 100 \mu \mathrm{m}$ image of this facet will offer an exposure time of $8.3 \mathrm{~ms}$ at a fluence of $65 \mathrm{MJ} / \mathrm{m}^{2}$. From Fig. 2 this fluence is more than adequate for plasma formation. However, our codes predict that this fluence cannot achieve the ultimate potential of this technique as regards specific impulse. Passively $Q$-switched, repetitively pulsed, diode-pumped solid-state lasers that weigh only $15 \mathrm{~g}$ are now available in the $1-\mathrm{W}$ average power range (Dunton, E., private communication, Litton-Airtron Corp., Los Angeles, June 2001). Nanosecond-duration pulses give 50-kW peak power, allowing us to access all materials and create temperatures high enough for very large $I_{\mathrm{sp}}(8000 \mathrm{~s}$ have been measured with nanosecond-duration laser pulses ${ }^{5}$ ).

Diode-pumped, glass fiber lasers offer an interesting alternative for achieving higher $\mathrm{CW}$ power with adequate brightness and small mass penalty. 
We continue to explore R-mode illumination. The most encouraging results in the literature ${ }^{13}$ for forward-peaked ablation plumes have given a polar distribution $\propto \cos ^{10} \theta$. We intend to measure the ablation polar distribution. We are planning experiments with a new optical design, which we believe can utilize this polar distribution without becoming contaminated during thruster lifetime.

We also continue to explore specially designed polymers for T-mode or R-mode operation. We believe these have tremendous potential for improving LPT performance.

\section{Acknowledgments}

This work was performed with the support of the U.S. Air Force Office of Scientific Research under STTR Phase I Contract F49620 98-C-0038 and STTR Phase II Contract F49620-00-C-0005. We gratefully acknowledge the assistance of Thomas Lippert and his team at the Paul Scherrer Institut, Zurich, in developing specially designed polymers for this work. We are also happy to acknowledge the tireless support to our work throughout this program provided by John Marquis, director of the Energy Conversion Research Laboratory at New Mexico Engineering Research Institute.

\section{References}

${ }^{1}$ Lang, R., O'Brien, S., Schoenfelder, A., Hagberg, M., Demars, S., and Li, B. "High Power, High Brightness Diode Lasers," 1998 Diode Laser Technology Review, U.S. Air Force Research Laboratory, AFRL/DELS, Kirtland AFB, NM, 1998

${ }^{2}$ Phipps, C. R., and Dreyfus, R. W., "Laser Ablation and Plasma Formation," Laser Microprobe Analysis, edited by A. Vertes, R. Gijbels, and F. Adams, Wiley, New York, 1993, Chap. 4, pp. 369-431.

${ }_{3}^{3}$ Haglund, R. F., Jr., Ermer, D. R., Papantonakis, M. R., Park, H. K. and Yavas, $\mathrm{O}$., "Phase Explosion and Ablation in Fused Silica Initiated by an Ultrashort-Pulse, Tunable Mid-Infrared Free-Electron Laser," Proceedings of the International Symposium on High Power Laser Ablation 2000 Vol. 4065, Society of Photo-Optical Instrumentation Engineers, Bellingham, WA, 2000, pp. 42-51.

${ }^{4}$ Phipps, C. R., Turner, T. P., Harrison, R. F., York, G. W., Osborne W. Z., Anderson, G. K., Corlis, X. F., Haynes, L. C., Steele, H. S., Spicochi, K. C., and King, T. R., "Impulse Coupling to Targets in Vacuum by $\mathrm{KrF}, \mathrm{HF}$ and $\mathrm{CO}_{2}$ Lasers," Journal of Applied Physics, Vol. 64, No. 3, 1988 $\mathrm{KrF}, \mathrm{HF}$ and $\mathrm{CO}_{2}$

${ }^{5}$ Phipps, C. R., and Michaelis, M. M., "Laser Impulse Space Propulsion," Journal of Laser and Particle Beams, Vol. 12, No. 1, 1994, pp. 23-54.

${ }^{6}$ Afanas'ev, Yu. V., Basov, N. G., Krokhin, O. N., Morachevskii, N. V., and Sklizkov, G. V.. "Gas-Dynamic Process in Irradiation of Solids," Soviet Physics-Technical Physics, Vol. 14, No. 5, 1969, pp. 669-676.

${ }^{7}$ Apostol, I., Vatanov, V. A., Mikheilesku, I. N., Morzhan, I., Prokhorov, A. M., and Fedorov, V. B., "Recoil Impulse Received by Metal Targets as Result of Interaction with Microsecond $\mathrm{CO}_{2}$ Lase Radiation," Soviet Journal of Quantum Electronics, Vol. 6, 1976, pp. 1119, 1120.

${ }^{8}$ Augustoni, A. L., Ermer, P. G., Heckler, R. T., Kuwashima, G. R., McKay, J. A., and Rudder, R. R., "The Interaction of High Energy Single Pulse XeF Laser Radiation with Solid Targets," U.S. Air Force Research Lab., AFWLLaser Radiation with Solid Targets," U.

${ }^{9}$ Combis, P., David, J., and Nierat, G., "Mesure des Effets Mécaniques dans les Expériences d'Interaction Laser-Matiere a Eclairement Modéré,'
Revue Scientifique et Technique de la Defense, CEL-Valenton No. 4, Centre des Etudes Limeil-Valenton, Villeneuve-Saint-Georges, France, 1992, pp. 59-75.

${ }^{10}$ McKay, J. A., and Laufer, P. M., "Survey of Laser-Produced Pressure and Impulse Data," Physical Sciences, Inc., Final Rept. PSI-1012/TR-757, New England Business Center, Andover MA, 1987, pp. 1-236.

${ }^{11}$ Duzy, C., Woodroffe, J. A., Hsia, J. C., and Ballantyne, A., "Interaction of a Pulsed XeF Laser with an Aluminum Surface," Applied Physics Letters, Vol. 37, No. 6, 1980, pp. 542-544.

${ }^{2}$ Gregg, D., and Thomas, S. J., "Momentum Transfer Produced by Focused Laser Giant Pulses," Journal of Appied Physics, Vol. 37, No. 7, 1966, pp. 2787-2789.

${ }^{13}$ Dreyfus, R. W. " $\mathrm{Cu}^{0}, \mathrm{Cu}^{+}$, and $\mathrm{Cu}_{2}$ from Excimer-Ablated Copper," Journal of Applied Physics, Vol. 69, No. 3, 1991, pp. 1721-1729.

${ }^{14}$ Phipps, C. R., Harrison, R. F., Shimada, T., York, G. W., Turner, T. P., Corlis, X. F., Steele, H. S., Haynes, L. C., and King, T. R., "Enhanced Vacuum Laser Impulse Coupling by Volume Absorption at Infrared Wavelengths," Laser and Particle Beams, Vol. 8, 1990, pp. 281-297.

${ }^{15}$ Rosen, D. I., Nebolsine, P. E., and Wu, P. K. S., "Laser Impulse Applications Research," Proceedings of the AIAA Conference on the Dynamics of High Power Lasers, AIAA, New York, 1978, paper VI.

${ }^{16}$ Rosen, D. I., Hastings, D.E. and Weyl, G.M.,"Coupling of Pulsed 0.35 $-\mu \mathrm{m}$ Laser Radiation to TitaniumAlloys," Journal of Applied Physics, Vol 53, No. 8,1982, pp. 5882-5890.

${ }^{17}$ Rosen, D. I., Mitteldorf, G., Kothandaraman, G., Pirri, A.N., and Pugh,

E. R., "Coupling of Pulsed 0.35- $\mu \mathrm{m}$ Laser Radiation to Aluminum Alloys," Journal of Applied Physics, Vol. 53, No. 4, 1982, pp. 3190-3200.

${ }^{18}$ Rudder, R. R., U.S. Air Force Research Lab., AFWL-TR-74-100, Kirtland AFB, NM, 1974, pp. 189-198.

${ }^{19}$ Shui, V. H., Young, L. A., and Reilly, J. P., "Impulse Transfer from Pulsed $\mathrm{CO}_{2}$ Laser Irradiation at Reduced Ambient Pressures," AIAA Journal, Vol. 16, 1978, pp. 649, 650 .

${ }^{20}$ Ursu, I., Apostol, I., Dinescu, M., Mihailescu, I. N., and Moldovan, M., "Plasma-Target Coupling in the Case of TEA-CO $\mathrm{CO}_{2}$ Laser Produced Breakdown in Front of a Solid Target," Optics Communications, Vol. 39, 1981, pp. 180-185.

${ }^{21}$ Pucik, T., and Crawford, R. C., "Optical Laser Impulse Coupling Data Package,” Logicon/R\&D Associates, RDA Rept. 2.28.90, Los Angeles, 1990.

${ }^{22}$ Weast, R. C. (ed.), Handbook of Chemistry and Physics, 58th ed., CRC Press, Cleveland, OH, 1978, pp. C-794, C-796, D-165, and E-10.

${ }^{23}$ Eshbach, O. W. (ed.), Handbook of Engineering Fundamentals, 2nd ed., Wiley, New York, 1955.

${ }^{24}$ Harper, C. A. (ed.), Handbook of Plastics and Elastomers, McGrawHill, New York, 1976, pp. 1-24 and 3-59.

${ }^{25}$ Phipps, C. R., Reilly, J. P., and Campbell, J. W., "Optimum Parameters for Laser-Launching Objects into Low Earth Orbit," Journal of Laser and Particle Beams, Vol. 18, No. 4, 2000, pp. 661-695.

${ }^{26}$ Gradshteyn, I. S., and Ryzhik, I. M., Table of Integrals, Series and Products, Academic Press, New York, 1965, Sec 2.161.1b, p. 67.

${ }^{27}$ Lippert, T., David, C., Hauer, M., Wokaun, A., Robert, J., Nuyken, O., and Phipps, C. R., "Polymers for UV and Near-IR Irradiation," Journal of Photochemistry Photobiology and Chemical Science (to be published).

R. P. Lucht Associate Editor 